\title{
Configuraç̄es do ensino superior e a formação profissional dos assistentes sociais: desafios para a intervenção*
}

\section{Configurations of university education and social workers' professional background: challenges for intervention}

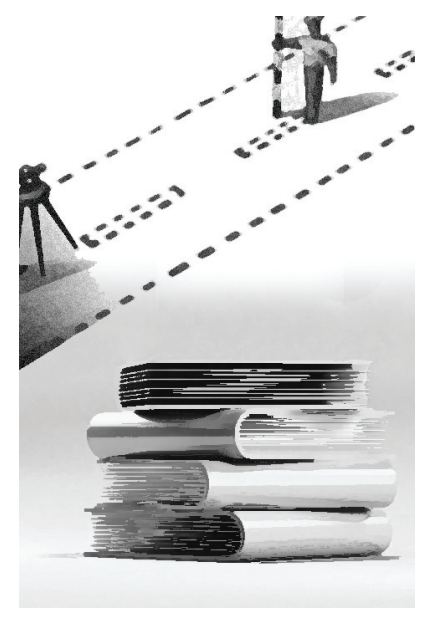

Isaura Isoldi de Mello Castanho e Oliveira**

Resumo: O tema central que orientou a palestra é o desafio docente de, frente aos desafios da intervenção e das atuais configurações do ensino superior público, privado e a distância formar profissionais assistentes sociais capazes de dar materialidade ao projeto ético político da profissão no cotidiano de seu trabalho.

Palavras-chave: Formação profissional. Caminhos do fazer. Habilitação técnico-operativa.

\begin{abstract}
The main issue of the article is the teaching challenge to form professional social workers able to materialize the ethical-political professional project in the everyday work, at the same time that such teaching has to face the challenges of both intervention and current configurations of public, private and distance university education.
\end{abstract}

Keywords: Professional background. Paths of action. Technical-operative capability.

* Este texto reproduz a palestra proferida pela autora no Terceiro Seminário Anual de Serviço Social promovido pela Cortez Editora, mantendo o tom coloquial.

** Assistente social; professora assistente e mestre do Curso de Serviço Social da PUC-SP, São Paulo/ SP, Brasil. E-mail: isoldioliveira@hotmail.com. 


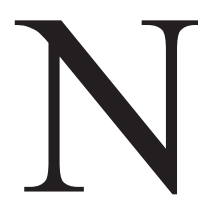

avego no barco do Serviço Social há mais de trinta anos, dando aulas diariamente, participando de todas as formulações e reformulações curriculares do curso de Serviço Social da PUC-SP, contribuindo com instâncias gestoras, na chefia de departamentos, na direção da então Faculdade de Serviço Social, na assessoria da pró-reitoria acadêmica e agora na coordenação de curso. São tantos anos quantos aqueles em que trabalhei como assistente social na ponta, no interior de um grande hospital público e na assessoria a um projeto novo de governo na gestão Luiza Erundina, na coordenação do trabalho com crianças e adolescentes em São Paulo, sem contar o trabalho de pesquisa e assessoria na implantação do Suas nos municípios de Diadema e Moji das Cruzes.

Toda essa experiência mostrou que certamente a bússola que orienta a formação profissional tem duas direções centrais que nos ajudam a não perder a rota:

1) A primeira é a discussão feita em nosso projeto curricular, ao afirmar que "os princípios norteadores do processo formativo são direcionados à formação de um profissional dotado de competência teórico-crítica, com uma sólida aproximação das vertentes do pensamento social contemporâneo e suas expressões teórico-práticas no Serviço Social a exigir a afirmação de trato teórico-metodológico rigoroso aliado a um atento acompanhamento histórico da dinâmica da sociedade". É por isso que o maior desafio está na articulação entre a profissão e a realidade social, certo que o Serviço Social não atua apenas sobre a realidade, mas na realidade.

2) A segunda é a definição do perfil do bacharel em Serviço Social estabelecido coletivamente pela Abepss para todo o território nacional:

- profissional que atua nas expressões da questão social, formulando e implementando propostas para o seu enfrentamento, por meio de políticas sociais públicas, empresariais, de organizações da sociedade civil e movimentos sociais;

- profissional dotado de formação intelectual e cultural generalista crítica, competente em sua área de desempenho, com capacidade de inserção criativa e propositiva no conjunto das relações sociais e no mercado de trabalho;

- profissional comprometido com os valores e princípios norteadores do código de ética do assistente social. 
Trata-se, portanto de formar um profissional que percebe a dimensão política de seu trabalho, no interior mesmo da contradição, na disputa de projetos e na construção de uma nova hegemonia...

Falo a partir desses cenários e desses nortes, especialmente de minhas salas de aula, dando ênfase especial e particular à dimensão formativa que contribua para dar materialidade ao Código de Ética, desmanchando crenças, valores e expectativas dos alunos, como única via possível para viabilizar nosso projeto ético-político no interior mesmo do exercício profissional e não só das proposições e debates acadêmicos. De fato, este é o trabalho central do professor. Retomemos o Código de Ética.

Como reconhecer a liberdade como valor ético central, e as demandas políticas a ela inerentes - autonomia, emancipação e plena expansão dos indivíduos sociais - se não me desvencilho de minhas amarras ideológicas, de minha escuridão cultural e das certezas por elas impostas de que as oportunidades estão aí para todos e quem não as aproveita fica sempre à margem, no fim da fila?

Como fazer a defesa intransigente dos direitos humanos e recusar o arbítrio e o autoritarismo sem começar por uma relação mais igual com os usuários, recusando o papel de polícia que investiga cada moeda que eles ganham e gastam, que estabelece o que é necessário e o que é supérfluo para as famílias, que determina — isoladamente — vias de inclusão/exclusão em programas e/ou benefícios?

Como trabalhar para ampliar e consolidar a cidadania, considerada tarefa primordial de toda a sociedade, com vistas à garantia dos direitos civis, sociais e políticos das classes trabalhadoras se desprezo a condição básica de cidadania — a participação dos usuários no controle das políticas e no uso do dinheiro público?

Como fazer a defesa do aprofundamento da democracia, enquanto socialização da participação política e da riqueza socialmente produzida se continuo achando que a riqueza advém de mérito e esforço?

Como me posicionar a favor da equidade e da justiça social, que assegure universalidade de acesso aos bens e serviços relativos aos programas e políticas sociais, bem como sua gestão democrática, se não estabeleço critérios democráticos e transparentes em meu trabalho e se não sou capaz de reconhecer igualmente o direito de cada um, e de me manter avessa a critérios de julgamento estritamente rigorosos e legais? Todos diferentes, todos iguais... 
Como me empenhar na eliminação de todas as formas de preconceito, incentivando o respeito à diversidade, à participação de grupos socialmente discriminados e à discussão das diferenças se em meu trabalho - e em minha vida - discrimino alcoólatras, homossexuais, prostitutas, mulheres que praticaram aborto ou que foram infiéis a seus companheiros?

Como trabalhar para a garantia do pluralismo, através do respeito às correntes profissionais democráticas existentes e suas expressões teóricas, e compromisso com o constante aprimoramento intelectual se não me dou conta da necessidade de fazer escolhas políticas, escolhas teóricas, não adenso o debate, nem me percebo tantas vezes eclética?

Como fazer a opção por um projeto profissional vinculado ao processo de construção de uma nova ordem societária, sem dominação-exploração de classe, etnia e gênero, se nem presto muita atenção a quem dou meu voto e, às vezes, até ajudo a eleger pessoas que representam só a classe dominante, ou que, ao contrário de Robin Hood, roubam dos pobres para dar aos ricos?

Como fazer a articulação com os movimentos de outras categorias profissionais que partilhem dos princípios de nosso Código e com a luta geral dos trabalhadores se nem de meu centro acadêmico ou de minha associação profissional eu participo?

Como manter compromisso com a qualidade dos serviços prestados à população e com aprimoramento intelectual, na perspectiva da competência profissional, se não conheço a política sob a qual meu trabalho está abrigado e se penso — bem escondidinho — que os pobres não precisam de muita qualidade no atendimento?

E, finalmente, como estar no exercício do Serviço Social sem ser discriminado, nem discriminar, por questões de inserção de classe social, gênero, etnia, religião, nacionalidade, opção sexual, idade e condição física se não me percebo discriminada e não percebo o quanto discrimino?

É disso que quero falar... Quase sempre somos chamadas a responder a questões polêmicas trazidas por nossos alunos: o que faz o assistente social? Quais são os objetivos da formação profissional? Por que a teoria não tem nada a ver com a prática? Por que, em alguns estágios, são distribuídas apostilas que discutem o SS de casos, de grupos e de comunidade? Por que cada caso não é um caso e tem a ver com os outros casos? 
Formar profissionais assistentes sociais exige levá-los a entender que o problema das famílias com as quais trabalham não é a má utilização do orçamento, por menor que seja a renda, e sim a falta de trabalho, salário, moradia, escola, condições de vida, igualdade social, garantia de direitos. Não objetivamos ensinar as famílias a utilizar melhor o dinheiro que não tem, e sim a conhecer a sua real situação, de forma a estabelecer caminhos de enfrentamento e superação. Sempre penso que atingi meus objetivos docentes quando os alunos conseguem enfrentar e superar seus aprendizados ideológicos, construídos à luz dos ensinamentos da assistente social Balbina Otoni Vieira (1948) quando advertia

podemos dizer que a base de tratamento dos problemas econômicos é a compreensão dos fatores que influem sobre a personalidade e se traduzem no uso do dinheiro [...]. O filho de pais abastados, como o indigente, podem crescer e ser adultos dependentes: o primeiro, porque os pais tudo lhe deram, o segundo porque a sociedade sempre proveu a família com as necessidades essenciais, sem que esta procurasse fazer qualquer esforço para obtê-las. [...] é necessário ensinar como gastar bem, aproveitar ao máximo a quantia disponível, a fim de cobrir todas as necessidades essenciais e o maior número de satisfações legítimas...

Não é isso que aprendemos no interior do tecido social? E é nesse âmbito que somos nós, assistentes sociais, que fazemos com que a população aprenda e apreenda quais são os critérios de seleção e passe a incorporá-los, criando um "código de linguagem" que organiza um discurso próprio que passa a ser de domínio da população e que a leva a "colorir" suas histórias de vida, para enquadrar-se nos critérios estabelecidos.

Formar profissionais assistentes sociais competentes exige levá-los a entender que ser assistente social é escolher trabalhar com as mais cruéis manifestações da questão social, com quase todas as misérias humanas.

Formar assistentes sociais exige incentivar nos alunos o movimento de ininterrupta curiosidade intelectual, a busca contínua do conhecimento, da verdade, do compromisso com os excluídos, da alegria e da responsabilidade no trabalho.

Formar profissionais assistentes sociais competentes exige levá-los a entender que ser assistente social é compreender que a luta por direitos é uma luta de classe e contra o capital, reafirmando com Marilda que 
o ponto de partida da análise é o de que a luta pela afirmação dos direitos é hoje também uma luta contra o capital, parte de um processo de acumulação de forças para uma forma de desenvolvimento social, que possa vir a contemplar o desenvolvimento de cada um e de todos os indivíduos sociais... (Iamamoto, 2009, p. 16)

Discutir a formação profissional — presencial sempre! — significa discutir e ensinar os Caminhos do fazer. Entender que a habilitação técnico-operativa é imperativa. Demarcar, com Marilda (2003) que não se pode reduzir o campo da reflexão ao "fazer profissional" e relegar para outros a tarefa de pensar e analisar a bagagem teórica que norteia esse fazer Precisamos realizar as ações profissionais entendendo as bases teórico-metodológicas e as determinações econômicas, políticas e ideológicas que estão nelas operando. É por isso que o ensino instrumental e técnico é fundamental em seu esforço de ensinar os alunos a compreender, estudar e desvendar quais são essas determinações e suas novas roupagens em cada quadra histórica.

Atendemos (é, atendemos... ou conversamos... ou recebemos... ou acolhemos... não importa!) pessoas todos os dias, durante todo o tempo, submetidas a sofrimentos infligidos pelo aprofundamento da questão social em suas expressões mais perversas e disfarçadas. E nosso desafio é construir o corredor de confiança entre o profissional e os usuários, desvelando o serviço que se pode prestar, com suas possibilidades e limites.

O espaço profissional não está dado em si mesmo! Encontra-se em permanente e dinâmico processo de redimensionamento, cabendo aos profissionais entender e detectar as tendências presentes na sociedade, apropriando-se das possibilidades historicamente dadas e transformando-as em propostas de traba1ho. O que está em jogo é a relação entre conhecimento e realidade, entre teoria e prática social!

Se no interior do movimento de reconceituação pudemos questionar a fundo o trabalho com casos, grupos e comunidades, talvez ainda não tenhamos nos recuperado completamente. Propomos orientação e acompanhamento social a indivíduos, grupos e familias; discutimos terapias, tratamentos, ajudas, direitos.

Precisamos construir sempre novas estratégias para formar, de fato, novos protagonistas que possam interferir no trabalho desenvolvido pelos profissionais, que possam rejeitar o codinome especialista em desenvolvimento social, como hoje são denominados os assistentes sociais e psicólogos da prefeitura de São Paulo! Assistentes sociais que possam fazer a diferença no interior de uma pro- 
fissão que trabalha no olho do furacão, que é contratada pelos dominantes para acalmar os dominados e que, imaginem vocês, escolheu dar voz, hora e lugar aos dominados, escolheu contribuir para a construção de uma nova hegemonia.

Lá se vão muitos e muitos anos quando eu, professora novinha, falei que precisavamos ensinar os alunos a trabalhar com as "questões sociais". Heresia! A professora Vicentina Velasco, inesquecível professora de Ética e Fundamentos Filosóficos na PUC-SP, me ensinou — em público - que não existiam questões sociais, e sim a questão social, produzida pela relação capital/trabalho.

Ensinou-me - e não mais esqueci - que o assistente social trabalha com as expressões da questão social. Nunca mais me esqueci também, e Yolanda trabalha isto, que o ensino da prática tem que possibilitar pensar, tem de proporcionar uma reflexão sobre a adequação entre meios e fins e nos levar a perguntar pelos próprios fins, ou seja, as implicações éticas e as direções estratégicas das nossas finalidades.

Sim, é certo que não trabalhamos com individuos e famílias para tratá-los ou para educá-los, tarefa que, em seu subtexto, embute a ideia de que os problemas estão apenas nas pessoas e nas relações que estabelecem, bastando fortalecê-las para que se abram novos caminhos.

A esse propósito, Rodrigues (2003), da Universidade Federal do Rio de Janeiro, lembra que as famílias com as quais trabalhamos não estão descoladas da desigualdade entre classes; desenham o mapa da fome, estão muitas vezes chefiadas por mulheres, são alvo prioritário das políticas públicas.

Entender que individuos e famílias carregam instantâneos fotográficos das expressões da questão social e aí ganham singularidade nos dirige ao trabalho de viabilização dos direitos e dos meios de exercê-los, sem viés terapêutico. Ora, para isso primeiro é preciso entender que as pessoas têm direitos e não lhes prestamos favores em nome do Estado ou do capital.

É preciso, principalmente, apreender e aprender a decodificar que

as condições de vida e de trabalho dos trabalhadores migram do ambiente privado e familiar para a esfera pública, através de lutas e movimentos sociais, exigindo seu reconhecimento enquanto necessidades de classe (Mota, 1998, p. 47)

Penso que o principal desafio da formação profissional aparece quando o estágio começa e os alunos parecem ter esquecido de tudo o que aprenderam 
nas salas de aula. O contato imediato com as pessoas parece não precisar de fundamentos teóricos, levando os alunos a se regerem, de início, pelas suas mais tradicionais crenças ideológicas, políticas e religiosas construídas pelo senso comum.

A formação profissional deve considerar que o trabalho do assistente social depende tanto dos resultados da análise da realidade como da intencionalidade e direção social impressa pelos sujeitos profissionais; é o que faz a diferença. Digo sempre a meus alunos que os assistentes sociais - como coletivo - seriam capazes de traçar o mais rico e colorido mapa da pobreza no Brasil, de desenhar as mazelas humanas e sociais que levam ao assédio e ao abuso sexual, à prática de homicídios, à violência doméstica, ao tráfico de drogas e de seres humanos, ao abandono de crianças e de adolescentes, à violência familiar e institucional contra eles etc.

Seriam, se fossem movidos sempre pelo sentido investigativo na ação profissional, se prestassem atenção ao seu trabalho, ao seu interlocutor. A formação profissional deve ser muito rigorosa no trato aprofundado da escolha do método de conhecimento do real e de ação profissional.

Andamos metidos em muitas polêmicas em torno da Lei de Estágio, do ensino a distância e das práticas terapêuticas, o que traz grandes repercussões para a formação profissional, seja as que nos levem a seu aligeiramento, as que nos imponham um perigoso viés rigorista ou que nos desviem de nosso foco principal no trabalho profissional direto com a população, que é apreender as determinações societárias que incidem na dinâmica da vida cotidiana dos indivíduos, considerando os indivíduos em sua singularidade, pois

prevalece nos fundamentos do projeto ético-político profissional do Serviço Social o entendimento do indivíduo como ser genérico e singular e não há espaços para nenhuma dicotomia e/ou antinomia entre sociedade e indivíduo. O entendimento do indivíduo simultaneamente como ser genérico e singular nos remete a considerar tanto as determinações societárias que possibilitam identificar a existência de um profundo processo de desigualdade social, como também valorizar, dentre muitas outras, as dimensões de gênero, raça/etnia, orientação sexual e geração. Historicizados em seu tempo histórico e em suas condições de vida e de trabalho, os usuários com os quais trabalhamos são pessoas concretas, com sonhos, desejos, frustrações e buscas incessantes para assegurar a possibilidade de continuação da vida em tempos de barbárie produzida pelo sistema do capital (CFESS, 2010, p. 11). 
A formação profissional tem de dar conta de preparar os alunos para 0 trabalho com essas pessoas concretas, sem desconhecê-las e sem adoecê-las entendendo que

nos diversos projetos profissionais do Serviço Social, podemos encontrar diferentes concepções de profissão, que passam por distintas compreensões acerca do objeto profissional, de seus objetivos, bem como sobre seu instrumental técnico-operativo. O debate acumulado sobre a intervenção profissional tem sido marcado por formulações e práticas vinculadas a diferentes projetos profissionais, cada uma delas atribuindo significações diferenciadas para o arsenal de instrumentos e técnicas utilizadas pelos assistentes sociais - cuja constituição se distancia de um todo homogêneo e meramente técnico. Tais diferenciações passam por variados entendimentos sobre a sociedade e a profissão, tangenciando a utilização do instrumental na consecução da prática. Dessa forma, afastamos qualquer possibilidade de autonomia do instrumental, pois ele também compõe o projeto profissional, como elemento fundamentalmente necessário à objetivação das ações profissionais; assim, o instrumental é parte da direção teórico-política da prática profissional. (Trindade, 2002, p. 26-27)

Acabo minha fala adaptando trechos do discurso de formatura que fiz para os alunos de 2009: "É bom nos lembrarmos, juntos, que escutar não é a mesma coisa que ouvir, como já nos dizia Vasconcelos em 2003

[...] a gente fica falando em escuta, escuta e escuta, e a maioria dos profissionais não escuta nada. Não estamos sabendo escutar mais. E quando escutamos ficamos surdos para o que as pessoas estão nos dizendo, não as processamos, não as entendemos, não vamos à raiz do que as pessoas estão colocando em nossas mãos. E queremos manejar conflitos!

Reivindica-se o direito de fazer terapias breves (ou longas!) querendo reiterar ainda - e uma vez mais - que as pessoas tem problemas e que seu manejo é caminho de solução.

É bom nos lembrarmos, juntos, que ver não é a mesma coisa que enxergar. Que conhecer não é a mesma coisa que saber. Que dormir na aula não ajuda a aprender. Que a população quer ser acolhida, e não disciplinada. Que trocamos nossos saberes profissionais com as sabedorias da população, organizada ou não. Que as verdades adolescentes deverão ser substituídas por dúvidas eternas! 
Aprendemos que nos forjarmos assistentes sociais significa explorar e desafiar nossos valores, questionar tudo o que nossos pais nos ensinaram, nos colocar no lugar do outro, trocar de sapato com o outro.

No interior da formação profissional trabalhamos com o cotidiano de estágio, com questões trazidas ao interior da sala de aula e nos corredores por jovens que, ainda que cheios de certezas, apresentam dúvidas quanto aos critérios de verdade e justiça, de certo e errado, de moral e de ético.

É bom nos lembrarmos, juntos, que é importante demais trabalhar o olhar curioso sobre o real, a pergunta inquieta que não aceita respostas fáceis e prontas. Precisamos desvelar preconceitos, aprendendo a botá-los para fora, em busca de superação. Precisamos aprender a respeitar e a reconhecer, no usuário de nossos serviços, o trabalhador dominado e oprimido, a quem olhamos nos olhos e não tratamos como mais um.

A formação profissional deve ajudar os alunos a redescobrir valores abafados pelo barulho da luta pela sobrevivência, como a solidariedade, a adesão à luta coletiva, a busca do sonho de cada um e de todos, o enxergar tranquilo dos pássaros e das plantas, o escutar atento do barulho do mar.

É é duro descobrir que, às vezes, sentimos raiva daqueles que colocam a nu as contradições da sociedade, dentro da nossa sala de trabalho: os alunos (e os assistentes sociais também...) brigam com os alcoólatras, com os drogaditos, com as profissionais do sexo, com os miseráveis e com os homicidas! Indignam-se com as crianças e com os homens e mulheres que estão nas ruas; assustam-se com os portadores de deficiências físicas e mentais; ficam com medo dos aidéticos, acham que as mães e pais que pedem ajuda são preguiçosos; ficam muito bravos com alguns supervisores eventualmente desatentos ou desligados! Enfim, descobrem que ser assistente social não é sinônimo de ser super-herói!

O embate cotidiano entre a formação teórica, o exercício da prática e os valores individuais permitirá o amadurecimento de nossos alunos e a descoberta - ainda que inicial - da relação entre o capital e o trabalho, que forja a constituição das classes em nossa sociedade e gera a exclusão social que bate às portas de nossa profissão.

O assistente social se defronta, cotidianamente com "candidatos" a cidadãos que buscam ajuda para satisfação de necessidades básicas de sobrevivência. Trata-se de uma profissão que lida com as misérias humanas, com o produto da exploração do homem pelo homem e que entende que 
dar conta da questão social, hoje, é decifrar as desigualdades sociais — de classes - em seus recortes de gênero, raça, etnia, religião, nacionalidade, meio ambiente etc. Mas decifrar, também, as formas de resistência com que são vivenciadas pelos sujeitos sociais. (Iamamoto, 1999)

A formação profissional há de considerar, ampliadamente, que a desigualdade de classes inclui, no interior da violência de classe, a violência de raça e de gênero, "a violência da sujeição à paisagem urbana inóspita que traz para o cotidiano todos os tipos de dificuldade, de transporte, de educação, de saúde, cultura e lazer; violência no interior da vida familiar; violência na dificuldade crescente de direito ao trabalho, cada vez mais especializado e discricionário; violência no imperativo de enfrentar filas para receber cartões para todos os benefícios sociais, depois de comprovar pobreza extrema; violência da exposição ao trabalho e à prostituição infantil; violência da ausência de perspectivas de vida" (Oliveira e Pavez, 2003, p. 6).

A formação profissional deve considerar que o assistente social é levado a escolher projetos profissionais repercutidos e confrontados com seu projeto de vida e de sociedade. O forjar dessa escolha se dá no processo histórico de amadurecimento pessoal, na "conversa" com os valores recebidos em casa, na família e na escola, na inserção social e política, no acesso ao conhecimento e à cultura, num caminho cheio de contradições, gerando dúvidas e inquietações, que atravessam o cotidiano. Só assim é possível superar

a prática empirista, reiterativa, paliativa, burocratizada, orientada por uma ética liberal-burguesa, que, de um ponto de vista claramente funcionalista, visava enfrentar as incidências psicossociais da "questão social" sobre indivíduos e grupos, sempre pressuposta a ordenação capitalista da vida social como um dado factual ineliminável. (Netto, 2005, p. 5)

Esse entendimento faz aflorar e traz para o confronto reflexões sobre os valores de nossa sociedade, exigindo um posicionamento ético e político frente à realidade, em todas as suas possibilidades, em busca de seu enfrentamento e transformação.

Passa por aí a reflexão que tenta compreender o sentido da realidade, na formação de assistentes sociais que tenham clareza de seu compromisso com os usuários, com base na liberdade, na democracia, cidadania, justiça e igualdade social, negando a "ética da neutralidade". 
Formar assistentes sociais - e tornar-se um deles - é caminho de mão única: é preciso estudar muito, ler o jornal todos os dias, silenciar para poder escutar, saber usar a palavra, fechar os olhos para poder enxergar, participar dos movimentos da categoria e dos trabalhadores, sonhar e buscar justiça, verdade e felicidade!

O recado maior que pretendi passar é que a formação profissional — presencial, rigorosa, sem qualquer aligeiramento, não mercantilista, sem concessões ao consumo e à privatização do conhecimento - é o único caminho de concretude ao projeto ético-político da categoria dos assistentes sociais.

Artigo recebido em ago./2010 - Aprovado em ago./2010

\section{Referências bibliográficas}

ABEPSS. Diretrizes curriculares para o curso de Serviço Social (Abepss/MEC, 1999). CFESS - Conselho Federal de Serviço Social. Serviço Social e reflexões críticas sobre práticas terapêuticas. Documento elaborado em março de 2010 para subsidiar reflexões e debates sobre a Resolução n. 569/2010, que não reconhece as diversas modalidades de terapias como competências e atribuições do/a assistente social e veda sua realização associada ao título de assistente social.

IAMAMOTO, Marilda Vilela. Debate na mesa-redonda atribuições privativas do assistente social e o Serviço Social Clínico. Promoção: Uerj e Cress, 7ª Região, maio 2003. (Mimeo.)

O Serviço Social na cena contemporânea. In: CFESS/Abepss. Serviço Social: direitos sociais e competências profissionais. Brasília, p. 16, 2009.

. O Serviço Social na contemporaneidade: trabalho e formação profissional. 2. ed. São Paulo: Cortez, 1999.

MOTA, Ana Elizabete (Org.). A nova fábrica de consensos: ensaios sobre a reestruturação empresarial, o trabalho e as demandas ao serviço social. São Paulo: Cortez, 1998.

NETTO, José Paulo O movimento de reconceituação: 40 anos depois. Serviço Social \& Sociedade, São Paulo, n. 84, p. 5-20, 2005.

OLIVEIRA, Isaura I. M. C.; PAVEZ, Graziela Acquaviva. Relatório final de pesquisa: em defesa da vida, contra a violência, 2003. (Mimeo.) 
RODRIGUES, Mavi P. Debate na mesa-redonda atribuições privativas do assistente social e o Serviço Social clínico. Promoção: Uerj e Cress, $7^{a}$ Região, maio 2003. (Mimeo.)

TRINDADE, Rosa Lúcia Prédes. Desvendando as determinações sócio-históricas do instrumental técnico-operativo do Serviço Social na articulação entre demandas sociais e projetos profissionais. Temporalis, Rio de Janeiro, ano III, n. 4, p. 26-27, 2002.

VASCONCELOS, Ana. Debate na mesa-redonda atribuições privativas do assistente social e o Serviço Social Clínico. Promoção: Uerj e Cress, $7^{\mathrm{a}}$ Região, maio 2003. (Mimeo.)

VIEIRA, Balbina O. A concessão de auxílios financeiros no tratamento social dos problemas econômicos. Serviço Social, São Paulo, n. 49, 1948. 